\title{
Outcomes of self-induced late pregnancy termination in women presenting to a tertiary hospital in the Eastern Cape Province, South Africa
}

\author{
S D Mandondo, ${ }^{1}$ FCOG (SA); G J Hofmeyr, ${ }^{2}$ DSc; F Mbengo, ${ }^{3}$ MPH; N T Mshweshwe-Paleka, ${ }^{4}$ MPH; T R Mavundla,${ }^{5}$ DCur \\ ${ }^{1}$ Walter Sisulu University and Eastern Cape Department of Health, East London, South Africa \\ ${ }^{2}$ Effective Research Care Unit, University of the Witwatersrand and Walter Sisulu University, East London, South Africa \\ ${ }^{3}$ Child Welfare South Africa QwaQwa, Phuthaditjhaba, South Africa \\ ${ }^{4}$ The Aurum Institute, Johannesburg, South Africa \\ ${ }^{5}$ Department of Health Studies, College of Human Sciences, University of South Africa, Pretoria, South Africa
}

Corresponding author: F Mbengo (fmbe2002@yahoo.com)

\begin{abstract}
Background. Little is known about the outcomes of self-induced pregnancy termination after 24 weeks' gestation, as previous studies have concentrated on outcomes before 24 weeks.

Objectives. To investigate the gestational age, misoprostol dosage, source of information on misoprostol, reasons for termination and outcomes of self-induced pregnancy termination after 24 weeks' gestation.

Methods. A quantitative, retrospective case series observational research design was utilised. Paediatric case summaries and the Perinatal Problem Identification Programme were used to collect data. Cases of self-induced pregnancy termination using misoprostol after 24 weeks gestation treated at a tertiary hospital in the Eastern Cape Province, South Africa, during the period 1 July 2011 - 1 January 2012 were identified and included in the study. Frequencies and proportions were used to analyse data.

Results. Eighteen known cases of self-induced pregnancy termination using misoprostol after 24 weeks' gestation were treated at the hospital during the 6-month study period. Misoprostol doses ranged from 400 to $1200 \mu \mathrm{g}$. Birth weight was $<500 \mathrm{~g}$ in 1 case $(6 \%), 500-$ $1499 \mathrm{~g}$ in $12(67 \%), 1500-1999 \mathrm{~g}$ in $2(11 \%),>2500 \mathrm{~g}$ in $1(6 \%)$ and unknown in $1(6 \%)$. Eleven of the babies (67\%) were born alive and $5(28 \%)$ were stillborn (1 further stillbirth (6\%) was classified as an abortion, $<500 \mathrm{~g}$ ). One baby $(6 \%)$ survived, and in 1 case $(6 \%)$ the pregnancy continued. Eight of the 10 neonatal deaths were early and 2 were late. The major cause of neonatal death was hyaline membrane disease $(n=8,44 \%)$. Other causes were hypoxia $(n=2)$, septicaemia $(n=2)$, necrotising enterocolitis $(n=2)$, pulmonary haemorrhage $(n=2)$ and intraventricular haemorrhage $(n=2)$. More than one cause applied in some cases. The maternal complications were manual removal of the placenta $(n=2,11 \%)$, ruptured uterus $(n=1,6 \%)$, and anaemia with blood transfusion $(n=1,6 \%)$.

Conclusions. Self-administration of misoprostol to induce pregnancy termination after 24 weeks' gestation contributes to preterm births and perinatal morbidity and mortality. The findings of this study show that there is a need to educate women on the perinatal and maternal risks associated with self-induced pregnancy termination at a late stage of gestation, availability of safe options for pregnancy termination, and contraceptive use and adherence. Healthcare workers need to be sensitive to the possibility that cases of apparent spontaneous preterm labour or birth may have been self-induced.
\end{abstract}

S Afr Med J 2018;108(11):965-971. DOI:10.7196/SAMJ.2018.v108i11.12979

Worldwide, every year $\sim 42$ million women with unintended pregnancies choose pregnancy termination, and nearly half of these procedures, $\sim 20$ million, are unsafe. ${ }^{[1]}$ Self-induced pregnancy termination is one form of 'unsafe' or 'illegal' pregnancy termination, defined as the procedure of self-administering pharmaceutical pills or traditional herbs or using other means to terminate a pregnancy. ${ }^{[2]}$ According to Bhattacharyya et al. ${ }^{[3]}$ self-induced terminations of pregnancy are often done clandestinely by untrained individuals or by the pregnant women themselves, so many of them go undocumented. For the purpose of the present study, self-induced late pregnancy termination was defined as self-administration of misoprostol to terminate pregnancy after 24 weeks' gestation.

There are many reported methods of unsafe pregnancy termination, including drinking toxic fluids such as turpentine, bleach or concoctions mixed with livestock manure; inserting herbal preparations into the vagina or cervix; placing a foreign body such as a twig, coat hanger or chicken bone into the uterus; or placing inappropriate medication into the vagina or rectum. ${ }^{[1]}$ Methods of external injury are also used, such as jumping from the top of stairs or a roof, or inflicting blunt trauma to the abdomen. ${ }^{[4]}$ In South Africa (SA) a commonly used method of self-induced pregnancy termination is taking misoprostol tablets, which are sold illegally in most townships and cities. ${ }^{\left[{ }^{5}\right.}$ Although misoprostol is not registered for use in pregnancy, it is a widely used and safe method of pregnancy termination ${ }^{[6,7]}$ in a clinical setting when done according to evidence-based protocols. A fundamental requirement for safety is ascertainment of the gestational age, as the uterus becomes progressively more sensitive to misoprostol during pregnancy. A safe dose in early pregnancy (before 20 - 24 weeks) may cause uterine rupture later in pregnancy. Self-administration without healthcare provider supervision is potentially dangerous.

The incidence of self-induced pregnancy termination is high, especially in low-resource settings. ${ }^{[8]}$ This is of great concern in view of the various adverse consequences associated with this practice. The 
World Health Organization ${ }^{[2]}$ has identified self-induced pregnancy termination as one of the preventable causes of maternal morbidity and mortality. It is estimated that $\sim 68000$ women die of self-induced pregnancy termination annually worldwide, making it one of the leading causes of maternal mortality. ${ }^{[1]}$ Furthermore, Singh ${ }^{[8]}$ observed that $\sim 5$ million women in the developing world are hospitalised each year for treatment of pregnancy termination-related complications such as haemorrhage and sepsis, and pregnancy termination-related deaths leave 220000 children motherless. Self-induced pregnancy termination also results in reproductive tract infections, infertility and a long-term risk of ectopic pregnancy, premature delivery and spontaneous abortion in subsequent pregnancies. ${ }^{[4]}$ Common sideeffects and complications of misoprostol-induced termination of pregnancy include gastrointestinal side-effects, abdominal cramps, bleeding, fever, chills, infection and rupture of the uterus. ${ }^{[9]}$

Self-induced pregnancy termination also has economic costs: for example, a recent study by Benson et al. ${ }^{[10]}$ estimated the costs of post-pregnancy termination care in the public health sector in Malawi at USD314 008 annually. The treatment of pregnancy termination-related complications may require resources such as blood products, antibiotics, oxytocics, anaesthesia, operating rooms and surgical specialists. The financial and logistical impact of treating complications can overwhelm the public healthcare system and divert limited resources from other critical healthcare programmes. Unmeasurable outcomes of self-induced pregnancy termination include loss of productivity and psychological harm. ${ }^{[1]}$

There are many reported risk factors associated with self-induced pregnancy termination. Empirical evidence shows that late gestational age, the method used, women's readiness to seek post-pregnancy termination care, the quality of the facility they reach, and the qualifications and attitude of the healthcare provider all influence the risk of preterm births, perinatal morbidity and mortality, and other pregnancy termination-related complications. ${ }^{[1]}$

With empirical evidence that self-induced pregnancy termination negatively affects women, their families, the public healthcare system and economic productivity, it is important for countries to formulate strategies to prevent it. Strategies include less restrictive pregnancy termination laws and increased contraceptive use. ${ }^{[1]}$ However, liberalisation of pregnancy termination laws does not guarantee the increased utilisation of legal pregnancy termination services. For example, evidence suggests that the legal pregnancy termination rate in SA is still low (6 per 1000 women), and many pregnancy terminations are still being performed illegally, despite the enactment of the Choice on Termination of Pregnancy Act (Act 92 of 1996) by the government to promote safe pregnancy termination. ${ }^{[11]}$ Although pregnancy termination is legal in SA, desperate women facing the financial burdens and social stigma of unintended pregnancy and believing that they have no other option continue to risk their lives by self-induced pregnancy termination. ${ }^{[1]}$ Poor contraception knowledge among women, sexual violence, including rape, and partner opposition to pregnancy are some of the reasons women fall pregnant unintentionally and seek termination. ${ }^{[12,13]}$ Inaccessibility of safe and legal pregnancy termination services and healthcare providers' negative attitudes towards women seeking these services are reported barriers to safe pregnancy termination. ${ }^{[14]}$

Previous studies ${ }^{[1,8,9,15]}$ on self-induced pregnancy termination using misoprostol have concentrated on outcomes before 24 weeks' gestation. Little is known about the outcomes after 24 weeks.

\section{Objectives}

This study sought to fill the gap in the existing body of knowledge by answering the following research question: what are the gestational age, misoprostol dosage, source of information on misoprostol, reasons for self-inducing pregnancy termination, and outcomes of self-induced pregnancy termination after 24 weeks' gestation?

\section{Methods}

A quantitative, retrospective case series observational research design was utilised. Paediatric case summaries and the Perinatal Problem Identification Programme were used to collect data on all known cases of self-induced pregnancy termination using misoprostol after 24 weeks' gestation treated at a tertiary hospital in the Eastern Cape Province, SA, during the period 1 July 2011 - 1 January 2012. Data were collected on demographic characteristics, gestational age at self-induced pregnancy termination, misoprostol dosage, reasons for self-inducing pregnancy termination, and outcomes. The hospital is a major referral health facility in the province, and performed 11860 deliveries during the period January 2010 - January 2011. ${ }^{[16]}$ Purposeful sampling was used to select cases. All known cases of selfinduced pregnancy termination using misoprostol after 24 weeks' gestation treated at the hospital during the study period were included in the study. We excluded cases of self-induced pregnancy termination using other methods, before 24 weeks' gestation, not treated at the hospital and outside the study period. Data were analysed by means of frequencies and proportions. The study was approved by the ethics committee of the tertiary hospital (letter dated 30 January 2012).

\section{Results}

There were 18 known cases of self-induced pregnancy termination using misoprostol after 24 weeks' gestation treated at the hospital between 1 July 2011 and 1 January 2012.

\section{Demographic data}

The women's ages ranged from 17 to 37 years, with a median of 26 . Sixteen women (88\%) were single, 1 (6\%) was married and $1(6 \%)$

\begin{tabular}{ll} 
Table 1. Demographic data $(N=18)$ & \\
\hline Category & $n(\%)$ \\
\hline Age (years) & $1(6)$ \\
$<18$ & $2(11)$ \\
$18-19$ & $7(39)$ \\
$20-27$ & $7(39)$ \\
$28-33$ & $1(6)$ \\
$\geq 34$ & \\
Marital status & $16(89)$ \\
Single & $1(6)$ \\
Married & $1(6)$ \\
Widow & \\
Employment status & $10(56)$ \\
Unemployed & $1(6)$ \\
Employed (formal) & $2(11)$ \\
Employed (informal) & $1(6)$ \\
Self-employed & $4(22)$ \\
Student/scholar & \\
Parity & $6(33)$ \\
0 & $8(44)$ \\
2 & $1(6)$ \\
3 & $3(17)$ \\
4 & $7(39)$ \\
Previous caesarean section & $1(6)$ \\
Previous termination of pregnancy & \\
&
\end{tabular}


was widowed. Eight women (44\%) were in their second pregnancy and 6 women $(33 \%)$ were in their first; only 3 women $(17 \%)$ and 1 woman (6\%) were in their fourth and third pregnancy, respectively. Of the women, 7 (39\%) had had previous caesarean sections, of whom $1(6 \%)$ presented with abruptio placentae and $1(6 \%)$ uterine rupture. One woman $(6 \%)$ had had a previous termination of pregnancy. Ten women (56\%) were unemployed, 1 (6\%) had formal employment, 2 (11\%) had informal employment, $1(6 \%)$ was self-employed and 4 (22\%) were students (Table 1).

\section{Clinical findings, misoprostol dosage, source of misoprostol information and reasons for self-inducing pregnancy termination}

Thirteen women (72\%) were tested for HIV, with 7 (39\%) testing negative and $6(33 \%)$ positive. Four women $(22 \%)$ refused HIV testing and $1(6 \%)$ had unknown HIV status. Nine women (50\%) did not book for antenatal care, 8 (44\%) booked for antenatal care locally, and $1(6 \%)$ booked for antenatal care $300 \mathrm{~km}$ away. Only 4 women (22\%) requested termination of pregnancy in the index pregnancy, with 3 (17\%) being declined termination because they were over 20 weeks' gestation, the legal maximum for termination of pregnancy for psychological or social indications. One woman (6\%) was 13 - 20 weeks pregnant when she applied for termination, but owing to service overload there were no beds until she reached 20 weeks (Table 2).

The gestational age at the time of taking misoprostol ranged from 24 to 39 weeks, with 8 women $(44 \%)>28$ weeks' gestation. Six women (33\%) had gestational ages ranging from 24 to 27 weeks, and gestational age was unknown in $4(22 \%)$. The misoprostol dosages ingested ranged from 400 to $1200 \mu \mathrm{g}$, with 10 women (56\%) taking $800 \mu \mathrm{g}$ orally. Two women (11\%) took $400 \mu \mathrm{g}$ orally, 2 (11\%) took $400 \mu \mathrm{g}$ orally and vaginally, and $1(6 \%)$ took $1200 \mu \mathrm{g}$ orally. The misoprostol dosage was unspecified in 3 women (17\%). Eleven women (61\%) received information on misoprostol through phone adverts/street vendors, 1 (6\%) through pamphlets in town, $1(6 \%)$ through family/friend, and $1(6 \%)$ through a general practitioner. The source of misoprostol information was unknown in 4 cases $(22 \%)$. The reasons given for self-inducing pregnancy termination

Table 2. Clinical findings, gestational age, misoprostol dosage, source of misoprostol information and reasons for self-inducing pregnancy termination $(N=18)$

\begin{tabular}{|c|c|}
\hline Description & $n(\%)$ \\
\hline \multicolumn{2}{|l|}{ HIV status } \\
\hline Positive & $6(33)$ \\
\hline Negative & $7(39)$ \\
\hline Refused test & $4(22)$ \\
\hline Not known & $1(6)$ \\
\hline \multicolumn{2}{|l|}{ Antenatal care } \\
\hline Booked & $8(44)$ \\
\hline Unbooked (casualty/general outpatient department) & $9(50)$ \\
\hline Booked $>300 \mathrm{~km}$ & $1(6)$ \\
\hline \multicolumn{2}{|c|}{ Termination of pregnancy requested in current pregnancy and declined, reasons } \\
\hline Gestational age $>20$ weeks & $3(17)$ \\
\hline 13 - 20 weeks, no beds so went over gestational age for termination & $1(6)$ \\
\hline \multicolumn{2}{|l|}{ Gestational age when misoprostol taken (weeks) } \\
\hline 24 & $4(22)$ \\
\hline $25-27$ & $2(11)$ \\
\hline $28-29$ & $3(17)$ \\
\hline $30-34$ & $4(22)$ \\
\hline 39 & $1(6)$ \\
\hline Unknown & $4(22)$ \\
\hline \multicolumn{2}{|l|}{ Misoprostol dosage } \\
\hline $400 \mu \mathrm{g}$ orally & $2(11)$ \\
\hline $800 \mu$ g orally & $10(56)$ \\
\hline $400 \mu \mathrm{g}$ vaginally and orally & $2(11)$ \\
\hline $1200 \mu \mathrm{g}$ orally & $1(6)$ \\
\hline Unknown & $3(17)$ \\
\hline \multicolumn{2}{|l|}{ Source of misoprostol information } \\
\hline Phoned advert/street vendor & $11(61)$ \\
\hline Given pamphlet in town & $1(6)$ \\
\hline Family/friend & $1(6)$ \\
\hline General practitioner & $1(6)$ \\
\hline Unknown & $4(22)$ \\
\hline \multicolumn{2}{|l|}{ Reason for self-inducing pregnancy termination } \\
\hline Family financial pressure & $8(44)$ \\
\hline Schooling/exams & $6(33)$ \\
\hline New job prospect & $3(17)$ \\
\hline Death of husband & $1(6)$ \\
\hline
\end{tabular}


were family financial pressure in 8 cases (44\%), new job prospects in $3(17 \%)$, wanting to go back to school or needing to write exams in 6 $(33 \%)$ and death of husband in $1(6 \%)$ (Table 2).

\section{Outcomes of self-induced late pregnancy termination}

Ten patients (56\%) presented in preterm labour (56\%) and in 2 cases (11\%) the baby was born before arrival. Other presentations were preterm premature rupture of membranes in 1 case $(6 \%)$, abruptio placentae in $1(6 \%)$, antepartum haemorrhage in $1(6 \%)$, septic retained placenta in $1(6 \%)$ and uterine rupture in $1(6 \%)$. One woman (6\%) failed to abort and was afraid that the baby might have birth defects. Antenatal steroids were given in 2 of the 11 cases in which the baby was born alive. The other 9 women presented in advanced labour or were diagnosed clinically as having an inevitable miscarriage although they subsequently delivered babies weighing $>500$ g.

When asked what they would do if the baby lived, 6 women (33\%) said that they would keep the baby, $5(28 \%)$ were unsure of what to do, $4(22 \%)$ said that they would give the baby up for adoption, and in 3 cases there was no information. The maternal complications were manual removal of the placenta in 2 cases (11\%), ruptured uterus in $1(6 \%)$ and anaemia with blood transfusion in $1(6 \%)$. There were no maternal complications in 14 cases $(78 \%)$. After delivery, contraception was offered to 10 women (56\%), with 3 (17\%) refusing contraception, 3 (17\%) opting for depot medroxyprogesterone acetate, $3(17 \%)$ choosing an intrauterine contraceptive device and 1 (6\%) choosing bilateral tubal litigation. Eight women (44\%) were not offered contraceptive counselling (Table 3 ).
In terms of neonatal outcomes, birth weight was $<500 \mathrm{~g}$ in $1(6 \%)$ $500-1499 \mathrm{~g}$ in 12 cases (67\%), $1500-1999 \mathrm{~g}$ in 2 (11\%), and $>2499 \mathrm{~g}$ in 1 (6\%). In 1 case birth weight was unknown, and 1 pregnancy continued. Eleven babies (61\%) were born alive, 5 (28\%) were stillborn, and 1 further stillbirth (6\%) was classified as a pregnancy termination $(<500 \mathrm{~g})$. Eight neonatal deaths $(44 \%)$ were early and $2(11 \%)$ were late. Four babies (22\%) received continuous positive airway pressure ventilation and $5(28 \%)$ received surfactant. The causes of neonatal death were hyaline membrane disease in 8 cases $(44 \%)$, hypoxia in $2(11 \%)$, septicaemia in $2(11 \%)$, necrotising enterocolitis in $2(11 \%)$, pulmonary haemorrhage in $2(11 \%)$ and intraventricular haemorrhage in $2(11 \%)$ (Table 4). More than one cause applied in some cases.

\section{Discussion}

The objective of the study was to investigate the gestational age, misoprostol dosage, source of information on misoprostol, reasons for inducing pregnancy termination and outcomes of self-induced termination of pregnancy after 24 weeks' gestation. The findings show that illegal use of misoprostol to self-induce pregnancy termination after 24 weeks contributes to preterm births and perinatal morbidity and mortality. This is a major concern in terms of SA's efforts to reduce pregnancy termination-related mortality and morbidity. For SA, reaching the United Nations (UN) Sustainable Development goals of reducing the maternal mortality ratio to $<70$ per 100000 live births, neonatal mortality to at least as low as 12 per 1000 live births and under-5 mortality to at least as low as 25 per 1000 live births by 2030 will be difficult if the public

\begin{tabular}{|c|c|}
\hline Description & $n(\%)$ \\
\hline \multicolumn{2}{|l|}{ Presentation } \\
\hline Preterm labour & $10(56)$ \\
\hline Preterm premature rupture of membranes & $1(6)$ \\
\hline Antepartum haemorrhage & $1(6)$ \\
\hline Abruptio placentae* & $1(6)$ \\
\hline Uterine rupture ${ }^{\star}$ & $1(6)$ \\
\hline Baby born before arrival & $2(11)$ \\
\hline Retained placenta & $1(6)$ \\
\hline Pregnancy continued, fear baby would have birth defects & $1(6)$ \\
\hline Antenatal steroids given (to 2 out of the 11 babies born alive) & $2(18)$ \\
\hline \multicolumn{2}{|l|}{ What will mother do if baby lives? } \\
\hline Adoption & $4(22)$ \\
\hline Keep baby & $6(33)$ \\
\hline Unsure & $5(28)$ \\
\hline Not recorded & $3(17)$ \\
\hline \multicolumn{2}{|l|}{ Maternal complications } \\
\hline Anaemia with blood transfusion & $1(6)$ \\
\hline Ruptured uterus & $1(6)$ \\
\hline Manual removal of placenta & $2(11)$ \\
\hline No complications & $14(78)$ \\
\hline \multicolumn{2}{|l|}{ Contraception offered after delivery } \\
\hline Intrauterine contraceptive device & $3(17)$ \\
\hline Depot medroxyprogesterone acetate & $3(17)$ \\
\hline Refused & $3(17)$ \\
\hline Bilateral tubal litigation & $1(6)$ \\
\hline Not offered/discussed & $8(44)$ \\
\hline
\end{tabular}




\begin{tabular}{|c|c|}
\hline Description & $n(\%)$ \\
\hline \multicolumn{2}{|l|}{ Neonatal outcome } \\
\hline FSB & $2(11)$ \\
\hline MSB & $3(17)$ \\
\hline ENND & $8(44)$ \\
\hline LNND & $2(11)$ \\
\hline Abortion & $1(6)$ \\
\hline Still pregnant & $1(6)$ \\
\hline Survived & $1(6)$ \\
\hline \multicolumn{2}{|l|}{ Birth weight (g) } \\
\hline $500-999$ & 9 (50) (7 ENND, 1 FSB, 1 MSB) \\
\hline $1000-1499$ & 3 (17) (1 ENND, 1 MSB, 1 alive) \\
\hline $1500-1999$ & 2 (11) (2 LNND) \\
\hline $2000-2499$ & 0 \\
\hline$>2499$ & $1(6)(\mathrm{FSB} / \mathrm{BBA})$ \\
\hline$<500$ & 1 (6) (abortion) \\
\hline Unknown weight & $1(6)(\mathrm{MSB})$ \\
\hline \multicolumn{2}{|l|}{ Treatment given to babies } \\
\hline Continuous positive airway pressure ventilation & $4(22)$ \\
\hline Surfactant & $5(28)$ \\
\hline \multicolumn{2}{|l|}{ Causes of death (more than one cause in some cases) } \\
\hline Hyaline membrane disease & $8(44)$ \\
\hline Necrotising enterocolitis & $2(11)$ \\
\hline Pulmonary haemorrhage & $2(11)$ \\
\hline Intraventricular haemorrhage & $2(11)$ \\
\hline Hypoxia & $2(11)$ \\
\hline Septicaemia & $2(11)$ \\
\hline
\end{tabular}

health burden of self-induced late pregnancy termination is not successfully addressed. ${ }^{[17]}$

Our patients' gestational ages ranged between 24 and 39 weeks, with 8 women $(44 \%)>28$ weeks' gestation. Women need to be educated on the dangers of terminating pregnancy at late gestational ages. It is known that the risk of death is greater after second- than first-trimester pregnancy termination. ${ }^{[18]}$ The further along the pregnancy is, the higher the mortality risk becomes. There is still difficulty in providing second-trimester pregnancy terminations in SA because women at this gestational age require admission, and the Choice on Termination of Pregnancy Act allows only doctors to perform the procedure. ${ }^{[1]}$ The provision of pregnancy termination-related services at a primary care level is an important strategy to address this challenge. These services can be decentralised by the training and use of mid-level health providers such as midwives, nurses, clinical officers and physician assistants to offer pregnancy termination care. ${ }^{[19]}$ Evidence from Nigeria shows that provision of pregnancy termination care by midlevel health providers is effective in reducing mortality and morbidity due to unsafe pregnancy termination. ${ }^{[15]}$

Of 4 women (22\%) who experienced maternal complications in this study, none died. A study by Mbele et al. ${ }^{[20]}$ in the west of Pretoria, SA, found a large reduction in maternal mortality and no change in maternal morbidity due to pregnancy terminations since the implementation of the Choice on Termination of Pregnancy Act. The current study was far too small to assess maternal mortality as an outcome. Women with pregnancy termination should be encouraged to seek medical care earlier so that complications can be detected and managed more successfully.
Eight women (44\%) in this study were not provided with postpregnancy termination family planning counselling. This was a missed opportunity. To reduce the risk of future unintended pregnancies, it is important to integrate post-pregnancy termination care and family planning services. A study by Ceylan et al ${ }^{[21]}$ has shown that after having a pregnancy termination, many women will accept contraception. A study in Zimbabwe found that contraceptive counselling and provision at the time of treatment reduced unintended pregnancies and repeat pregnancy terminations by $50 \%$ over 1 year compared with post-pregnancy termination patients who did not receive such services. ${ }^{[22]}$

In the present study the misoprostol dosages ingested ranged from 400 to $1200 \mu \mathrm{g}$, with 11 women (61\%) taking $\geq 800 \mu \mathrm{g}$ orally. This is of concern, as the misoprostol had been ingested without healthcare provider supervision. It has been shown that the self-administration of misoprostol without such supervision is not safely effective and could result in the need for hospitalisation. ${ }^{[7]} \mathrm{A}$ randomised controlled trial by Dickinson et al. ${ }^{[23]}$ found that administration of $400 \mu \mathrm{g}$ misoprostol is more effective and associated with fewer sideeffects than dosages of $>400 \mu \mathrm{g}$. There is a need to educate women on the risks associated with the use of high dosages of misoprostol to terminate pregnancy at a late gestational age. Misoprostol should be administered under the supervision of a skilled healthcare provider, after confirmation of the gestational age.

The reasons for self-inducing pregnancy termination given in this study were financial pressure in 8 cases (44\%), wanting to go back to school or needing to write exams in $6(33 \%)$, new job prospects in $3(17 \%)$ and death of husband in $1(6 \%)$. The unintended 
pregnancies could have been avoided by the use of contraception. Women should therefore be offered contraceptive counselling and a choice of appropriate methods in order to reduce unintended pregnancies. It should be noted that 8 women in this study (44\%) chose to self-induce pregnancy termination because of financial pressure. Continued gender inequality, particularly in many African communities, has a significant effect on prevention of unwanted pregnancy and women's access to pregnancy termination-related care. ${ }^{[24]}$ In these communities, women cannot seek medical treatment without the permission of their husbands, mothers-in-law or other family members, even if they are experiencing severe illness. This practice often delays women's access to care and can lead to serious complications or death. Furthermore, women's limited economic resources also contribute to delays in seeking services. ${ }^{[24]}$ Unsafe pregnancy termination can therefore be prevented by increased autonomy so that women can make their own decisions regarding family planning and choice of contraceptive method.

In the present study, a woman who ingested misoprostol at 24 weeks' gestation failed to abort and feared that the baby would have birth defects. Although studies ${ }^{[25]}$ have found an association between misoprostol exposure before 10 weeks and birth defects, evidence shows no clear causal relationship between later misoprostol exposure and birth defects, and the absolute risks of these defects is extremely low at 24 weeks' gestation. ${ }^{[26]}$ Women can therefore be reassured that there is little danger of harm to the baby after failed pregnancy termination at this gestational age.

In this study, women received information on misoprostol through informal networks such as phone adverts, street vendors, pamphlets, family members and friends. This is very worrying, as the misoprostol was self-administered without the supervision of a skilled healthcare provider. Although some studies ${ }^{[27,28]}$ have advocated provision of misoprostol over the counter, as in Brazil in 1986, this would be hazardous in SA owing to inappropriate dosing and may be associated with incomplete pregnancy termination. The provision of misoprostol over the counter necessitates medical supervision as well as easy access to medical care in case of emergencies, so is not a viable option in SA. ${ }^{[28]}$ For a successful outcome when misoprostol is provided over the counter, women would need to recognise that they are pregnant, estimate the duration of pregnancy, select the appropriate regimen, adhere to the correct protocol, manage adverse reactions and seek care if medical attention is needed, notice and cope with expulsion of the embryo, and recognise complete/ incomplete pregnancy termination. ${ }^{[27]}$ These criteria are unlikely to be fulfilled in most resource-constrained societies in Africa. Establishment of friendly pregnancy termination care services will go a long way towards alleviating this problem. ${ }^{[29]}$

The major causes of neonatal death in this study were hyaline membrane disease in 8 cases (44\%), hypoxia in $2(11 \%)$, septicaemia in $2(11 \%)$, necrotising enterocolitis in $2(11 \%)$, pulmonary haemorrhage in $2(11 \%)$ and intraventricular haemorrhage in 2 (11\%) (more than one cause applied in some cases). These findings concur with a study by Allanson et al. ${ }^{[30]}$ on the perinatal mortality and associated maternal complications in an SA province that found the main causes of neonatal death to be immaturity $(48.7 \%)$ and hypoxia (40.6\%). Preventing self-induced pregnancy terminations can reduce the trauma and costs of treating preterm babies only for them to die later.

The present study has important implications for practice and research on self-induced pregnancy termination. Studies on selfinduced pregnancy termination using misoprostol have concentrated on perinatal outcomes before 24 weeks' gestation. ${ }^{[1,8,9,15]}$ The study makes an important contribution to the current body of knowledge concerning the outcomes of self-induced pregnancy termination after 24 weeks.

\section{Study limitations}

The main limitations of the study are the retrospective design and the small sample size. As most women who self-induce pregnancy termination do not reveal this fact to medical services, the number of known cases presenting over 6 months is probably an underestimation of the scale of the problem. Owing to the small sample size, the generalisability of the findings is limited. The high-risk profile of patients admitted at the tertiary hospital, a referral facility admitting mostly high-risk patients, could also have influenced the findings, and there may well be other unknown factors. Although the interpretation of the data from this study is limited, it is possible that self-induced late pregnancy termination is contributing significantly to preterm births, perinatal morbidity and mortality. To assess the overall extent to which preterm births and perinatal morbidity and mortality rates are due to self-induced late pregnancy termination, further research with larger sample sizes should be conducted.

\section{Conclusions}

Self-induced late pregnancy termination using misoprostol contributes to preterm births and perinatal morbidity and mortality and poses a threat to reaching the UN Sustainable Development goals of reducing global maternal, neonatal and under-5 mortality by 2030 . Women who self-induce pregnancy termination are at significant risk and require counselling on the perinatal risks of pregnancy termination at a late stage of gestation, the risk of illegal self-medication with misoprostol and availability of safe options for pregnancy termination, as well as long-term follow-up with counselling on contraceptive use and adherence. Health workers need to be sensitive to the possibility that cases of apparent spontaneous preterm labour or birth may have been self-induced.

\section{Declaration. None.}

Acknowledgements. Special thanks for the support of the tertiary hospital where the study was conducted, without which this study would have been impossible.

Author contributions. SDM conducted the primary research under the supervision of GJH. FM, NTM-P and TRM expanded the research scope and contributed to the first draft of the manuscript. All authors revised and approved the final draft of the manuscript.

Funding. None

Conflicts of interest. None.

1. Haddad LB, Nour NM. Unsafe abortion: Unnecessary maternal mortality. Rev Obstet Gynecol 2009;2(2):122-126

2. World Health Organization. Unsafe Pregnancy Termination: Global and Regional Estimates of the Incidence of Unsafe Pregnancy Termination and Associated Mortality in 2003. 5th ed. Geneva: WHO, 2007. http://www.who.int/reproductivehealth/publications/unsafe_pregnancy termination/9789241596121/en (accessed 27 February 2017).

Bhattacharyya SK, Saha SP, Bhattacharrya S, et al. Consequences of unsafe abortion in India - a case report. Proc Obstet Gynecol 2011;2(2):12.

Grimes DA, Benson J Singh S, et al. Unsafe pregnancy termination: The preventable pandemic. Lancet 2006;368 (9550):1908-1919. https://doi.org/10.1016/S0140-6736(06)69481-6

2006;368 (9550):1908-1919. https://doi.org/10.1016/50140-6736(06)6981-6 5. Hofmeyr GJ. Misoprostol in obstetrics and gynaecology - unregistered, dangerous and essential. S Afr
Med J 1998;88(5):535-536.

6. Carbonell L, Varela, L, Velazco FC, Sanchez C. The use of misoprostol for termination at $<9$ weeks of gestation. Eur J Contracept Reprod Health Care 1997;2(3):181-185.

Blanchard K, Winikoff B, Coyaji K, et al. Misoprostol alone - a new method of medical abortion? J Am Med Womens Assoc 2000;55(3 Suppl):189-190.

8. Singh S. Hospital admissions resulting from unsafe pregnancy termination: Estimates from 13 developing countries. Lancet 2006;368 (9550):1887-1892. https://doi.org/10.1016/S01406736(06)69778-X

9. Ho PC, Bluementhal PD, Gemzell-Danielsson K, et al. Misoprostol for the termination of pregnancy with a live fetus at 13 to 26 weeks. Int J Gynecol Obstet 2007;99 (Suppl 2):178-181. https://doi. org/10.1016/j.ijgo.2007.09.007

10. Benson J, Gebreselassie H, Manibo MA, et al. Costs of postpregnancy termination care in public sector health facilities in Malawi: A cross-sectional survey. BMC Health Serv Res 2015;15:562. https://doi, org/10.1186/s12913-015-1216-2 
11. De Roubaix M. Ten years hence - has the South African choice on Termination of Pregnancy Act, Act 92 of 1996, realised its aims? A moral-critical evaluation. Med Law 2007;26(1):145-177.

12. Jewkes RK, Gumede T, Westway M, et al. Why are women still aborting outside designated facilities in metropolitan South Africa? BJOG 2005;112 (9):1236-1242. https://doi.org/10.1111/j.1471-
in in metropolitan

13. Mundigo AI. Determinants of unsafe induced pregnancy termination in developing countries. In: Warriner IK, Shah IH, eds. Preventing Unsafe Pregnancy Termination and its Consequence Priorities for Research and Action. New York: Guttmacher Institute, 2006:51-71. http://www.who.ir reproductivehealth/publications/unsafe_abortion/0939253763.pdf (accessed 8 October 2018).

14. Mhlanga RE. Abortion: Development and impact in South Africa. Br Med Bull 2003;67:115-126.

15. International Seminar on 'The Health, Social and Economic Consequences of Unsafe Pregnancy Termination' in San Juan del Rio, Mexico, 10 - 12 November 2010. http://archive.iussp.org/Activities/ abortion/Report10.pdf (accessed 22 February 2018).

16. Mandondo SD. A retrospective comparative study of monthly rates of low birth weight babies and extremely low birth weight babies over 13 months at East London Hospital Complex from January 2010 - January 2011. MMed dissertation. Mthatha: Walter Sisulu University, 2012.

17. United Nations. Transforming Our World: The 2030 Agenda for Sustainable Development. Resolution adopted by the General Assembly on 25 September 2015. New York: United Nations, 2015

18. Bartlett LA, Berg CI, Schulman HB, et al. Risk factors for legal induced pregnancy terminations-related mortality in the United States. Obstet Gynecol 2004;103(4):729-737. https://doi.org/10.1097/01.
matlets mortality in the United St

19. World Health Organization. Safe Abortion: Technical and Policy Guidance for Health Systems. 2nd ed. Geneva: WHO, 2012. http://www.who.int/reproductivehealth/publications/unsafe abortion/9789241548434/en/ (accessed 22 February 2018).

20. Mbele AM, Snyman L, Pattinson RC. Impact of the Choice on Termination of Pregnancy Act on maternal morbidity and mortality in the west of Pretoria. S Afr Med J 2006;96(11):1196-1198. https:// www.ncbi.nlm.nih.gov/pubmed/17167707 (accessed 22 February 2018).

21. Ceylan A, Ertem M, Saka G, et al. Post pregnancy termination family planning counselling as a tool to increase contraceptive use. BMC Public Health 2009;9:20. https://doi.org/10.1186/1471-2458-9-20

22. Johnson BR, Ndhlovu S, Farr SL, et al. Reducing unplanned pregnancy and pregnancy termination in Zimbabwe through post pregnancy termination contraception. Stud Fam Plann 2002;33(2):195-202.
23. Dickinson JE, Evans SF. The optimization of intravaginal misoprostol dosing schedules in secondtrimester pregnancy termination. Am J Obstet Gynecol 2002;186(3):470-474. https://doi.org/10.1067/ mob.2002.121085

24. Hord CE, Benson J, Potts JL, et al. Unsafe pregnancy termination in Africa: An overview and recommendations for action. In: Warriner IK, Shah IH, eds. Preventing Unsafe Pregnancy Termination and its Consequences: Priorities for Research and Action. New York: Guttmacher Institute, 2006:115150.

25. Hofmeyr GJ, Milos D, Nikodem VC, et al. Limb reduction anomaly after failed misoprostol pregnancy termination. S Afr Med J 1998;88(5):566-567. http://www.ajol.info/index.php/samj/article/ viewFile/149001/138503 (accessed 22 February 2018)

26. Population Council, Gynuity Health Projects. Critical Issues in Reproductive Healthcare: Misoprosto and Teratogenicity: Reviewing the Evidence. Meeting report, May 22, 2002. New York: Population Council and Gynuity Health Projects, 2002. http://gynuity.org/downloads/mtg_rep_miso_teratogen en.pdf (accessed 27 February 2017).

27. Ellertson C, Elul B, Winikoff B. Can women use medical pregnancy termination without medical supervision? Reprod Health Matters 1997;5(9):149-161. https://doi.org/10.1016/S09688080(97)90019-7 28. Elul B, Hajri S, Ngoc NTN, et al. Can women in less-developed countries use a simplified medical Adesiyun A, Ojabo A. Unsupervised medical pregnancy termination with misoprostol among adolescent - what is the prospect of demedicalise pregnancy termination in sub-Saharan Africa? Open adolescent - what is the prospect of demedicalise pregnancy termination in

30. Obstet Gynecol $2011 ; 1: 234-237$. https://doi.org/10.4236/ojog.2011.14046
30. Allanson ER, Muller M, Pattinson RC. Causes of perinatal mortality and associated maternal Allanson ER, Muller M, Pattinson RC. Causes of perinatal mortality and associated materna
complications in a South African province: Challenges in predicting poor outcomes. BMC Pregnancy Childbirth 2015;15:37. https://doi.org/10.1186/s12884-015-0472-9

Accepted 7 May 2018. 